\title{
"MULHER FELIZ É MULHER CASADA. "UMA DISCURSIVIZAÇÃO DO CASAMENTO NO JORNAL DAS MOÇAS NA DÉCADA DE 50.
}

\author{
1. Bolsista PIBIC/FABESP Naiane Santos Couto, Graduando em Letras Vernáculas, Universidade Estadual de Feira \\ de Santana, e-mail: nannensc@ hotmail.com \\ 2. Professora Doutora Palmira Virginia Bahia Heine Alvarez, Departamento de Letras e Artes, Universidade Estadual \\ de Feira de Santana, e-mail:pavibheine@gmail.com
}

PALAVRAS-CHAVE: Discurso, Mulher, Casamento.

\section{INTRODUÇÃO}

O presente trabalho visa discutir a construção da imagem da mulher e do casamento no periódico Jornal das Moças na década de 50. Tendo como arcabouço teórico à Análise de Discurso de Linha Francesa (ADLF) que tem como precursor Michel Pêuchex, propõe-se discutir o modo que a ideologia e as condições produção alicerçam as perspectivas de casamento e o papel do sujeito mulher em vários aspectos na sociedade pela ótica da revista supracitada.

Neste contexto o sujeito mulher está continuamente associado ao ambiente doméstico, ou a profissões que são vistas como prolongamento do lar, para a mulher casada, no entanto é prioritário os cuidados com a casa, ao marido e filhos. Sendo o matrimônio parte essencial da família e este um dos fundamentos de uma sociedade moralmente sadia, é viável a análise de como são construídas as ideologias do casamento na década de 50 .

Assim esta pesquisa pretende contribuir para o reconhecimento das representações relativas ao sexo feminino e aos lugares sociais e discursivos que a mesma pertence.

\section{MATERIAL E MÉTODOS OU METODOLOGIA (ou equivalente)}

A pesquisa em Análise de Discurso não tem um caráter quantitativo, nem uma metodologia definida aprioristicamente.

A análise ocorreu em três etapas primeiro a leitura da exterioridade linguística do texto na procura de elementos que se direcionam para o discurso ,colocando o dito em conexão com não dito assim examinando os possíveis sentidos. Na segunda etapa buscou-se observar o funcionamento dos sentidos, a partir da identificação do deslizamento deste além dos indícios do funcionamento da ideologia.

Por fim a análise inclinou-se sobre o a observação dos sentidos de feminilidade através da análise das marcas da ideologia e do interdiscurso e silêncio identificando o sentido que foi construído a cerca do que é ser mulher.

RESULTADOS E/OU DISCUSSÃO (ou Análise e discussão dos resultados)

A Proposta deste trabalho foi identificar e analisar acerca (não tem espaço. Não é a cerca da discursivização da mulher no Jornal das Moças na década de 50 e por consequente colaborar para os estudos entre discursos e questões relativas a gênero.

Ao longo do processo de análise foi possível identificar o modo como a ideologia dominante agiu na construção de sentidos, conduzindo a mulher a ocupar determinados lugares que eram considerados essencialmente femininos, dentre eles, o lugar do lar e do casamento.Assim, observou-se a construção discursiva da mulher a partir do trabalho da ideologia que era difundida pelos veículos de comunicação de um modo geral e, especificamente, pela Revista Jornal das Moças na década de 50 
As imagens analisadas a seguir, foram retiradas da revista Jornal das Moças no período da década de 50. A figura 1 é uma das imagens que compõem o corpus selecionado para análise dos dados. Nele, duas mulheres conversam e o bate-papo gira em torno do tema casamento.

\section{FIGURA 01}

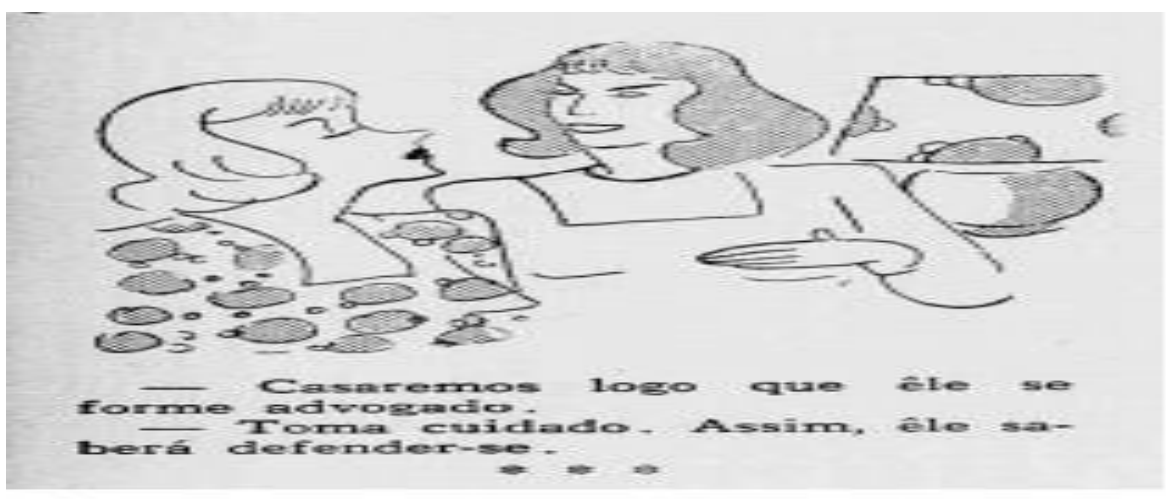

A figura 1 foi selecionada da seção Traças e Troços do periódico Jornal das Moças da década de 50. Está seção tinha como finalidade o entretenimento para suas leitoras, veiculando piadas e imagens engraçadas. Na parte não verbal, aparece a imagem de duas mulheres vestidas à moda da época, conversando. A que está à direita, esboça um sorriso e a que está à esquerda está com um ar pensativo. Na parte verbal do exemplo em questão existe um diálogo entre duas mulheres jovens que conversam sobre o casamento e as etapas para a realização deste. O texto que aparece é:Casaremos logo que ele se forme advogado. _ toma cuidado, assim ele saberá defender-se.

Pelo trabalho da ideologia dominante, mulheres e homens eram conduzidos a ocuparem esferas diferentes em relação ao casamento: para a mulher casar é algo natural, um desejo embutido na espera da formatura do noivo. Para o homem, o casamento é algo negativo, a ponto de a interlocutora afirmar que o noivo vai saber defender-se depois que se tornar advogado. Tais sentidos de que o casamento era algo bom para a mulher podem ser recuperados diante das condições de produção da época. $\mathrm{Na}$ década de 50, o sujeito mulher era responsável por gerenciar e manter a engrenagem familiar, funcionando de acordo com os padrões vigentes da década. Portanto, a finalidade primeira da mulher era casar, ser boa esposa e boa mãe. Sobre isso Simone Beauvoir assevera:

O destino que a sociedade tradicionalmente propõe à mulher é o casamento. Em sua maioria, ainda hoje, as mulheres são casadas, ou foram, ou se preparam para sê-lo, ou sofrem por não sê-lo. (BEAUVOIR 2009, p.547)

Pode-se então, perceber que o destino naturalizado da mulher é o matrimônio, cabendo a ela, portanto, o titulo de "rainha do lar", e encarregada da manutenção da prole, desta forma observar-se o funcionamento da ideologia através do silenciamento, ao dizer que destino final do sujeito mulher é o casamento, silenciam-se, pois, possibilidades de êxito pleno em outros papéis propostos.

No enunciado 1, a personagem usa a conjunção “..logo que...” que indica uma condição para a realização do casamento,logo observa-se a formação discursiva (FD) 
que alegar que o sujeito mulher vai causar problemas ao marido no casamento e este deverá aprender a se defender. Tal enunciado retoma do interdiscurso o sentido positivo de casamento em relação à mulher e negativo em relação ao homem:. Para este último, o casamento era um fardo, pois ele teria que sustentar financeiramente a mulher e a família, já que o trabalho fora de casa não era bem visto para o sexo feminino. Assim, o não dito e a posição que ocupa o sujeito revela o funcionamento da ideologia no que se refere ao local social da mulher, conduzindo-a a ocupar uma das posições na sociedade diferente da ocupada pelo homem, já que à mulher foi designado o papel de dona de casa e ao sexo masculino o lugar "natural" de provedor financeiro.

O enunciado 2 promove a observação do funcionamento do interdiscurso, pois, aqui o sujeito mulher identifica-se com FD anterior. Ao utilizar, contudo o verbo no imperativo ao lado da palavra cuidado “...Toma cuidado..”, retoma o que foi dito ressignificando o sentido,logo que o sujeito mulher em questão preocupa-se com súbito despertar do homem e a descoberta dos "reais" interesses femininos. Assim percebe-se então, que ambas compartilham da mesma posição ideológica que naturaliza esta a esfera doméstica.

\section{FIGURA 02}

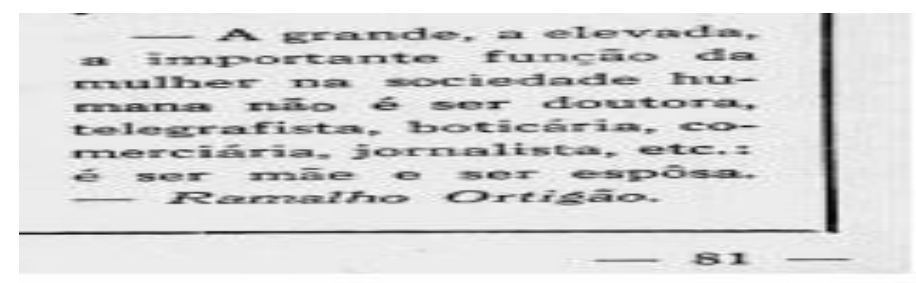

Na figura 03 o enunciado em questão há a seguinte afirmação. “A grande, a elevada, a importante função da mulher na sociedade humana não é ser doutora, telegrafista, boticária, comerciária, jornalista, etc. é ser mãe e ser esposa. traz em suma a definição do papel do sujeito mulher na sociedade de acordo com a ideologia vigente, que mantém a família como a mais preciosa jóia, um dos pilares da sociedade.

Ao longo do exemplo pode-se contemplar o relato de uma gama de possibilidades de funções fora da esfera domestica, as quais o sujeito mulher pode dedicar-se ". ser doutora, telegrafista, boticária, comerciária, jornalista, etc. mas o trecho destaca que a função primordial e mais importante da mulher é se dedicar ao lar no trecho:"“A grande, a elevada, a importante função da mulher na sociedade humana...”. O sujeito discursivo autor do enunciado também identifica-se com a formação discursiva a qual diz que lugar de mulher é no lar cuidando do marido e dos filhos.

Portanto, mais uma vez a construção da ideia do que ser é ser mulher é efetivada através do funcionamento ideológico, pois, apesar de ser possível a mulher trabalhar, está não deve desvincular-se de sua função inata que é “... ser mãe e ser esposa".

A mulher deveria se restringir ao seu "espaço natural", o lar, evitando toda sorte de contato e atividade que pudesse atraí-la para o mundo público. A medicina fundamentava essas concepções em bases cientificas, mostrando que o crânio feminino, assim como toda a sua constituição biológica, fixava o destino da mulher: 
ser mãe e viver no lar, abnegadamente cuidando da família. (DEL PRIORE 2004, p 592)

Nesse contexto, observa-se que a incorporação das mulheres ao mercado de trabalho e na esfera pública em geral, deveria ser restrita e não desvinculada do lar. A presença da mulher casada no campo de trabalho deveria se dar de modo cauteloso, pois, poderia gerar o abandono do lar não permitindo que as mesmas realizassem bem as suas funções maternais e domésticas ou seja a atuação feminina no mercado de trabalho era considerada uma coação à ordem pública.

Os já ditos juntamente com os não ditos sobre o que é ser mulher fomenta o funcionamento da ideologia. Embora sexo feminino também tenha conquistado o campo de trabalho na década de 50, neste mesmo período ocorreu uma retração no que diz respeito à mulher casada, pois segundo o Jornal Das Moças ao sair para trabalhar a dona de casa iria fragmentar seu tempo e fragilizar a sua eficácia nos trabalhos domésticos e cuidados com o marido e filhos além da perca da sua feminilidade.

Pode-se constatar o estranhamento do sujeito mulher ao almejar os ambientes profissionais no texto 03 , pois este não é seu lugar social "natural", pois o casamento é o ápice da realização feminina. Portanto a ideologia funciona através dos mecanismos da propaganda do periódico para solidificar as concepções de gênero que atribuem papeis específicos para o homem a este é dado o lugar de autoridade,e a mulher lugar de total submissão.

Assim o seu papel do sujeito mulher como mãe e esposa não pode ser alterado. $\mathrm{O}$ Desempenho feminino é parte primordial na consolidação de um lar feliz e tranqüilo, recai isto mais uma vez sobre "os seus ombros" agravando a desigualdade entre os sexos.

Conforme os elementos indicados, pode -se concluir que as materialidades co o propagandas, piadas e outras veiculadas na revista Jornal das Moças funcionavam como difusores da ideologia dominante na década de50. Através dos periódicos era possível a normatização dos sentidos, relativos à mulher e ao seu papel no casamento, como ser boa esposa e totalmente submissa ao marido.

Os exemplos selecionados para a análise constatam as formações ideológicas do que é ser mulher na sociedade e qual é sua função principal nela.Deste modo mesmo que a mulher ocupe outros lugares sociais segundo a ideologia disseminada pelo Jornal das Moças a mulher estará sempre ligada a imagem doméstica.

\section{REFERÊNCIAS}

HEINE, Palmira. Tramas e Temas em Análise do Discurso. 1.ed. Curitiba, PR: CRV, 2012 .

ORLANDI, Eni Puccinelli. Análise de Discurso: princípios e procedimentos. 8. ed. Campinas: Pontes, 2009.

ORLANDI,Eni Puccinelli.As formas do silêncio:No movimento dos sentidos.6. ed.Campina,SP Editora da Unicamp,2007.

BEAUVOIR, Simone de. O segundo Sexo;tradução de Sèrgio Milliet .- 3. Ed. - Rio de Janeiro :Nova Fronteira,2016

DEL PRIORE, Mary, História das mulheres no Brasil / Mary Del Priore (org.); Carla Bassanezi (coord. de textos). 7. ed. - São Paulo: Contexto, 2004. 